IRSTI 29.19.16; 29.19.04

\title{
Optimal geometrical parameters of porous layer in silicon solar cells
}

\author{
Z. Zh. Zhanabaev, K. K. Dikhanbayev and T. Yu. Grevtseva* \\ National Nanotechnological Laboratory of Open Type, \\ al-Farabi Avenue, 71, Almaty 050040, Kazakhstan \\ *e-mail: tatyana.grevtseva@kaznu.kz
}

\begin{abstract}
In the present work we have proved theoretically and experimentally that porous silicon layers with optimal thickness can be effectively used as anti-reflection coatings in solar cells and panels. In our work we have taken into account joint mechanisms of generation and recombination of free electrons and holes in porous silicon films stimulated by photons. Experimentally these films have been grown by method of electro-chemical etching. Regularities of morphology of surfaces of the films have been investigated by use of scanning electron microscopy. Results of scanning electron microscopy, measuring of short-circuit current, open circuit voltage, and values of etching time necessary for growth of the films with required characteristics have shown that in case value of thickness of the porous layer is approximately equal to two thirds of electron diffusion length, than efficiency of the solar cell with porous layer increases by $30 \%$ in comparison with the corresponding value in the absence of texturing.
\end{abstract}

Keywords: porous silicon, solar cell, efficiency, nanostructure, photovoltaics.

PACS numbers: 84.60.Jt; 68.55.Jk; 85.60.-q; 68.37.Hk.

\section{Introduction}

Renewable resources are the so called green energy sources that provide smaller impact to external environment than conventional energy sources. Because of this transformation of solar energy into electrical energy is an important scientific and technical problem related to perspective directions of future energetics.

Solar cells and panels as usual have relatively small efficiency. Because of this it's important to reduce reflectance of photons from surfaces of the solar cells for maximization a number of photons absorbed by a semiconductor surface to convert energy of incident light into electrical energy. So, since middle of the last century, methods for separation of electrons and holes in doped semiconductors, heterostructures, and various chemical compounds due to photon action of is an important research problem [1-9].

Among the great variety of methods used for increasing of solar cells efficiency, we can distinguish a method of texturing of their surfaces used for reducing of photon reflection [10-16]. As usual, for texturing of surfaces of silicon solar cells can be used acid texturization, reactive ion etching, and mechanical texturization [17-19]. Using of method of electro-chemical etching let us construct a solar cell as films with porous surfaces, for example, porous silicon (por-Si) with pore sizes about $10-10^{3} \mathrm{~nm}[20,21]$. Porous silicon is a nanostructured material attracting considerable attention of scientists because of its unique electrical and optical properties.

Changes in morphology of the films by texturing provide an antireflection effect (about 10\%), and give a possibility to increase efficiency of the solar cell in the same order. Obviously, these data are average. Resulting photoelectromotive force in the films depends on combination of many physical and geometric factors such as mechanisms of electrons and holes generation and recombination in semiconductors, wavelength of an effective part of solar radiation spectrum, topological and metric characteristics of porous layers. It's natural to expect existence of optimal sets of parameters characterizing these factors. We do not know the purposeful studies in this direction, although many experimental facts about the role of individual parameters are known. Universal recommendations for choosing of an optimal set of parameters can be obtained as a result of integration of theory and experiment. 
Aim of the present work is theoretical estimation of thickness of porous silicon layer located above pn-junction necessary for maximal electron generation due to photons action with taking into account recombination of electrons and holes, as well as comparison of theoretical results with experimental data.

\section{Theory and experiment}

A doped layer of $n$-type semiconductor contains nanosize pores decreasing reflection of photons with energy $\hbar w$ and wavelength $\lambda$. Diameter $(d)$, pore height $(x)$ defined according to front-face area, and distance between them $(l)$ have the same order as $\lambda$. This leads to realization of antireflection effect. Thickness of the porous level $L$ must be approximately equal to diffusion length of current carriers $L_{D}$, i.e. to the distance in which their concentration decreases significantly (in $e$ times). In case $L>L_{D}$, number of redundant electrons knocked out by photons is small. In case $L>L_{D}$, number of electrons recombined with holes is big. So, the problem is in determination of a relative distance $x / L_{D}$ describing balance of these two effects. As usual, diffusion length $L_{D}$ is estimated as

$$
L_{\text {д }}=\sqrt{D t},
$$

where $D$ is coefficient of diffusion of current carriers in a certain semiconductor, $t$ is their lifetime. It's more convenient to estimate $L_{D}$ via the Debye radius as

$$
L_{D}=\frac{V_{T}}{w_{0}}=\sqrt{\frac{k T \varepsilon}{N e^{2}}}=4,9 \sqrt{\frac{e T\left({ }^{\circ} K\right)}{N\left(c m^{-3}\right)}},
$$

where $V_{T}$ is thermal velocity of current carriers, $w_{0}$ is frequency of free oscillations of electrons, $N$ is concentration of extra charge carriers, $e$ is elementary electronic charge, $\varepsilon$ is relative dielectric permittivity of a medium, $T\left({ }^{\circ} K\right)$ is absolute temperature.

$\varepsilon=1$ for air inside of pores, $\varepsilon=11,8$ for silicon. Number of redundant electrons and holes generated per second in a unit volume of a semiconductor by a photon with energy $\hbar w$ can be expressed as

$$
N=\beta W / \hbar w, \hbar w \geq E_{g},
$$

where $W$ is power of solar radiation in a bulk layer with sufficient thickness equal to $1 / 4$ of optical wavelength $\lambda=w c /(2 \pi \sqrt{\varepsilon})$ corresponding to maximal photon absorption, $E_{g}$ is bandgap of the semiconductor, $\beta$ is quantum efficiency.

Diffusion length is a measurable physical parameter with size about a micron. So, it's necessary to define $x_{*} / L_{D}$, where $x_{*}$ is optimal thickness of porous layer.

Number of electrons $N$ in a surface layer with thickness $\lambda / 4$ can be defined via Eq. (3). Let us consider variations of $N(x)$ along the $p$-njunction. Number of electrons generated due to photon influence is proportional to pores height $x$ :

$$
N_{g}=g p x \hbar w, \quad 0 \leq p \leq 1,
$$

where $g$ is generation factor of electrons along $x$ direction, $p$ is porosity of the film.

Number of recombined pairs consisting of electrons and holes is proportional to variations of $p$ and $x$ :

$$
N_{z}=z p(1-p) x\left(L_{D}-x\right)
$$

where $z$ is recombination coefficient.

Joint probability of realizing of two independent statistical processes of generation and recombination is

$$
P\left(N_{g}, N_{z}\right)=\frac{g z p^{2}(1-p)}{N^{2}} \hbar w x^{2}\left(L_{D}-x\right) .
$$

Maximum condition of $P\left(N_{g}, N_{z}\right)$ on $p$ and $x$ can be given as

$$
\begin{gathered}
\left.\frac{\partial P\left(N_{g}, N_{z}\right)}{\partial x}\right|_{x=x_{*}}=2 x_{*}\left(L_{D}-x_{*}\right)-x_{*}^{2}=0, \\
x_{*}=\frac{2}{3} L_{D},
\end{gathered}
$$

$$
\left.\frac{\partial P\left(N_{g}, N_{z}\right)}{\partial p}\right|_{p=p_{*}}=2 p_{*}\left(1-p_{*}\right)-p_{*}^{2}=0,
$$




$$
p_{*}=\frac{2}{3} \text {. }
$$

Optimal thickness of porous level is $2 / 3$ of diffusion length for electrons at porosity is equal to $p=p *=2 / 3$.

At more detailed analysis we must take into account that porosity $p$ depends of length of pores, i.e. $p=p(x)$. Because of this we can consider Eqs. (8) and (9) as a system of interacting equations. Dependence $p=p(x)$ can be specified theoretically via relation between lacunarity (filling of space) $1-p$ and fractal dimension of porous level. At $x>>y \approx z \quad(y, z$ are lateral sizes of pores $)$ we have $\gamma=D-d \geq 0.1$ ( $D$ and $d$ are fractal and topological dimensions, correspondently). Dependence $p(x)$ is relatively weak. These singularities are typical for porous semiconductor films.

Let us consider a possibility of experimental observation of the regularity described by Eq. (7). Measurement of porosity of nanostructured films and verification of Eq. (8) represent a standing along experimental problem.

For our experiments we used a $p$-type monocrystalline silicon film. Thickness of this film was 350 micrometers, resistivity was $12 \mathrm{Ohm} \cdot \mathrm{cm}$, $p$ - $n$-junction was formed by use of thermo-diffusion of phosphorus. Thickness of $n^{+}$-layer was about 700-1500 nm and comparable with electron diffusion length. Because of this after etching the film contains pores with sizes smaller than distance to $p$ - $n$-junction. Scheme of a solar cell based on porous silicon is shown in Figure 1.

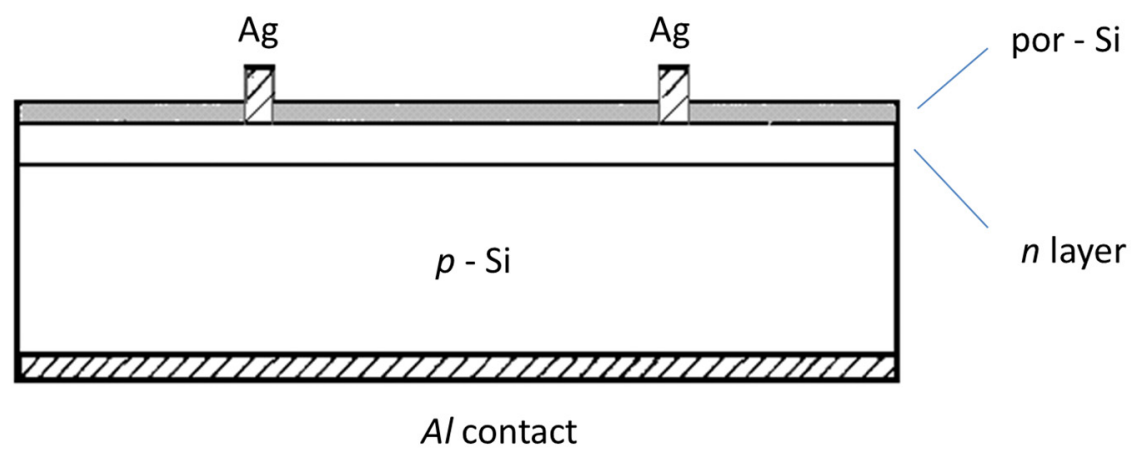

Figure 1 - Scheme of a solar cell based on porous silicon

The silver-aluminum contact was obtained by deposition of metallic $\mathrm{Ag}$. Porous silicon was obtained by electrochemical anodizing of surface of $n^{+}$-layer at different values of current density and etching time. Electrochemical anodizing was fulfilled in electrolyte $H F$ : ethanol in the ratio 1:1 at anodizing current density $20 \mathrm{~mA} / \mathrm{cm}^{2}$.

Increasing of anodizing current density and etching time lead to increasing of thickness of porous layer in direction to the plane containing $p-n$ junction. In order to find an effective thickness of silicon porous layer $x *$ corresponding to maximal value of short-circuit current of the solar cell we used etching of diffusion $n$-layer of the solar cell with different time durations.

We obtained images of micro-structure of crosssection of porous silicon near the $p$ - $n$-junction. For this aim we used a scanning tunneling microscope (SEM). In order to better visualize of porous structure layers of $p$ - $n$-junction we used a high concentration solution $H F$ and bright illumination from tungsten lamp of the end face of the sample.

Figure 2(a) demonstrates SEM-image of crosssection of porous silicon obtained at short time used for etching of $n$-layer. Figure 2(b) corresponds to long-term etching time. 


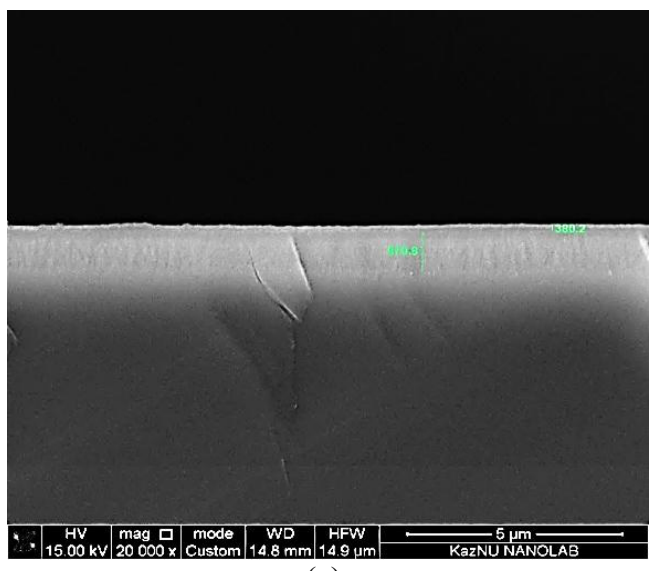

(a)

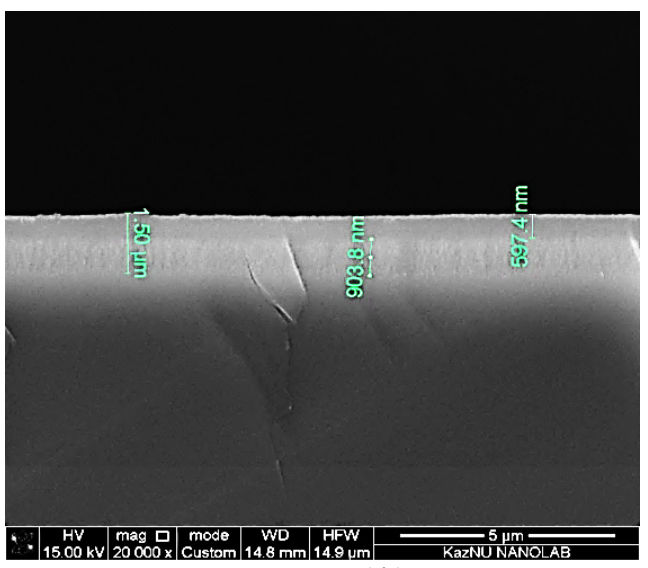

(b)

Figure 2 - SEM-images of cross-section of solar cell with porous silicon film

SEM-images contain areas of $p$ - $n$-junction, $n$ layer (thickness is $1,5 \mathrm{mkm}$ ) and porous silicon layer (thickness is $903,8 \mathrm{~nm}$ ) of the solar cell.

We measured values of short-circuit current $I_{\text {sh.c. }}$. in porous layer at illumination of tungsten incandescent lamp with power $87 \mathrm{~mW} / \mathrm{cm}^{2}$. Also we defined open-circuit voltages and the duty cycle of the volt-ampere characteristic of the solar cell. At first, the output parameters of polished solar cell without a porous layer were measured. Then we measured these parameters for silicon films with different thickness of porous layer. Figure 3 confirms the existence of effective thickness of porous level corresponding to maximal value of short-circuit current density of the solar cell. Location of nanopores was defined from the SEM images shown in Figures 2(a), (b). Maximal shortcircuit current $22,1 \mathrm{~mA} / \mathrm{cm}^{2}$ in $n$-layer of the solar cell corresponds to etching time $10 \mathrm{sec}$ and thickness of porous level $420 \mathrm{~nm}$. Value of shortcircuit current increases by $30 \%$ of its initial value measured in case of absence of the porous layer. Changing of solar cell efficiency with increasing of thickness of porous $n$-layer in the direction of $p-n$ junction is shown in Figure 4. Efficiency of the solar cell containing porous layer with thickness $420 \mathrm{~nm}$ is $35 \%$ greater than efficiency of a solar cell without of porous layer.

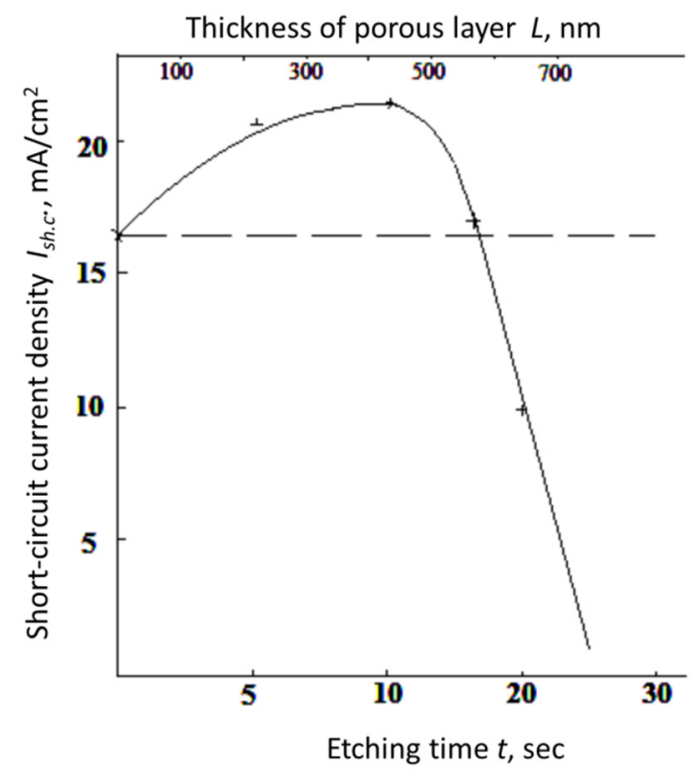

Figure 3 - Dependence of short-circuit current density of the solar cell on thickness of porous layer proportional to etching time 
Figures 3 and 4 show that values of optimal thickness of porous layer necessary for maximum of short-circuit current $\left(x_{*, I}\right)$ and solar cell efficiency $\left(x_{*, W}\right)$ are equal to $x_{*, I}=0,55$ and $x_{*, W}=0,70$, correspondently. These results are close to theoretical value $x_{*, W} \approx \frac{2}{3} L_{D}$ (is case of acceptance $L_{D} \approx 600 \mathrm{~nm}$ according to Figure 4).

Thickness of porous layer $L, \mathrm{~nm}$

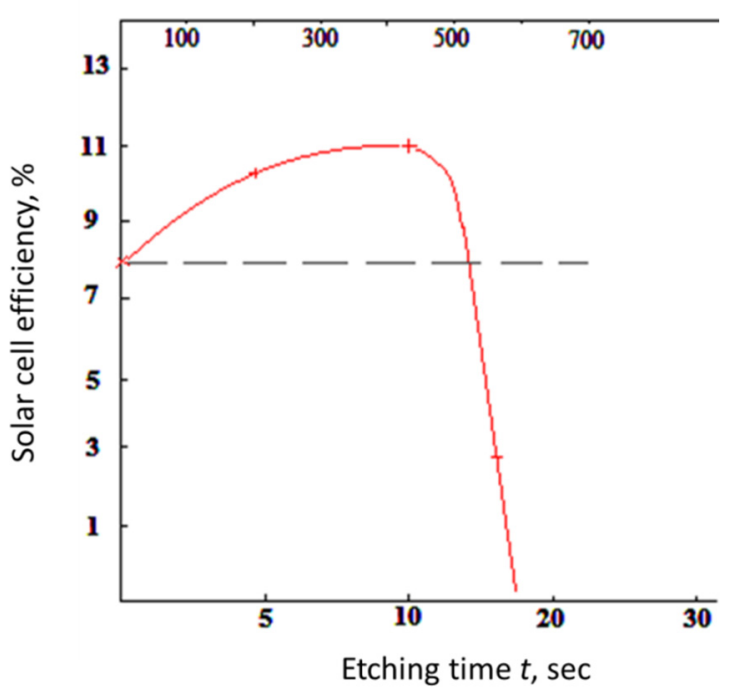

Figure 4. Dependence of solar cell efficiency on thickness of porous $n$-layer in the direction of $\mathrm{p}$-n-junction

\section{Conclusions}

Technology of texturing of solar cell surfaces widely used in photovoltaics in order to provide anti-reflection effects and passivation of recombination of charge carriers requires a theoretical justification. In the paper, we have shown theoretically and experimentally the existence of optimal depth of texturing in the form of porous silicon layer. Optimal values of porosity of working part of the solar cell are also described by our theory.

Results of the present work can be used for significant increasing of efficiency of solar cells (up to $35 \%$ of the efficiency without a porous layer). Especially important that the fact of existence of an optimal set of solar cell parameters proved in the present paper can have a universal application for improvement of various technologies (electrochemical powder technology, laser surface treatment technology, technology of using organic elements, etc.).

\section{Acknowledgments}

This work was supported by the Committee of Science of the Ministry of Education and Science of the Republic of Kazakhstan (Grant AP05132854).

\section{References}

1. Zh.I. Alferov. Istoriya i budushee poluprovodnikovih geterostructur // Fizika i technika poluprovornikov. - 1998. - Vol. 32. -No.1. - P. 3-18. (in Russian)

2. P.A. Shilyaev, D.A. Pavlov. Poluprovodnikovii geterostructuri: geteroperehod. - N. Novgorod: NGU, 2009. - 18 p. (in Rusian).

3. M.S. Nechaev, L.Yu. Pahashuk. Kvantovo-himicheskoe issledovanie novih redoks-mediatorov na osnove kompleksov medi I kobal'ta dlya fotoelectrohimicheskih solnechnih batarei // Vestnik MGU, - 2012. - No.6. - P. 6770. (in Russian). 
4. R. Loganathan, M. Jayasakthi, K. Prabakaran, R. Ramesh, P. Arivazhagan, K. Baskar. Studies on dislocation and surface morphology of $\mathrm{Al}_{\mathrm{x}} \mathrm{Ga}_{\mathrm{x}}-\mathrm{N} / \mathrm{GaN}$ heterostructures grown by MOCVD // Journal of Alloys and Compounds. 2014. - Vol. 616. - P. 363- 371.

5. L.E. Vorob'ev, L.G. Golub, S.N. Danilov, E.L. Ivchenko, D.A. Firsov, V.A. Shaligin. Opticheskie yavleniya v poluprovodnikovih kvantovo-razmernih structurah. - St.Petersburg: Izdatel'stvo SPbGTU, 2000. - 156 p. (in Russian).

6. Y.-T. Lua, A.R. Barron. Nanopore-type black silicon anti-reflection layers fabricated by a one-step silverassisted chemical etching // Physical Chemistry Chemical Physics. - 2013. - Vol. 15. - P. 9862-9870.

7. M. Ge, J. Rong, X. Fang, Ch. Zhou. Porous doped silicon nanowires for lithium ion battery anode with long cycle life // Nano Letters. - 2012. - Vol. 12. - P. 2318-2323.

8. K.A. Gonchar, L.A. Osminkina, R.A. Galkin, M.B. Gongalsky, V.S. Marshov, V.Yu. Timoshenko, M.N. Kulmas, V.V. Solovyev, A.A. Kudryavtsev, V.A. Sivakov. Growth, structure and optical properties of silicon nanowires formed by metal-assisted chemical etching // Journal of Nanoelectronics and Optoelectronics. - 2012. - Vol. 7 , - No.6. - P. 602-606.

9. V. Sivakov, S. Christiansen. Novel discovery of silicon // Journal of Nanoelectronics and Optoelectronics. 2012. - Vol. 7. - P. 1-7.

10. H. Lindstrom, A. Holmberg, E. Magnusson, S.E. Lindquist, L. Malmqvist, A. Hagfeldt. A new method for manufacturing nnostructured electrodes on plastic substrates // Nano Letters. - 2001. - Vol. 1, - No.2. - P. 97-100.

11. G.G. Untila, A.P. Pavlov, A.Yu. Poroikov, T.V. Rahimova, Yu.A. Mankelevich, T.N. Kost, A.B. Chebotareva, V.V. Dvorkin. Modelirovanie opticheskih svoistv kremnievih solnechnih elementov, teksturirovannih V-obraznimi pronikaushimi kanavkami // Fizika i technika poluprovornikov. - 2011. - Vol. 45, - No. 10. - P. 1410-1416. (in Russian).

12. P. Panek, M. Lipinski, J. Dutkikewicz Texturization of multicrystalline silicon by wet chemical etching for silicon solar cells // Journal of Materials Science. - 2005. - Vol. 40. - P. 1459-1463.

9. H.F.W. Dekkers, F. Duerinckx, J. Szlufcik, J. Nijs. Silicon surface texturing by reactive ion etching // OptoElectronics Review. - 2000. - Vol. 8, - No.4. - P. 311-316.

13. U. Gangopadhyay, S.K. Dhungel, K. Kim, U. Manna, P.K. Basu, H.J. Kim, B. Karunagaran, K.S. Lee, J.S. Yoo, J. Yi. Novel low cost chemical texturing for very large area industrial multi-crystalline silicon solar cells // Semiconductor Science and Technology. - 2005. - Vol. 20. - P. 938-946.

14. Zh. Xi, D. Yang, W. Dan, Ch. Jun, X. Li, D. Que. Texturization of cast multicrystalline silicon for solar cells // Semiconductor Science and Technology. - 2004. - Vol. 19. - P. 485-489.

15. J.D. Hylton, A.R. Burgers, W.C. Sinke. Alkaline etching for reflectance reduction in multicrystalline silicon solar cells // Journal of The Electrochemical Society. - 2004. - Vol. 151. - No.6. - P. 408-427.

16. K. Tsujino, M. Matsumura, Y. Nishimoto. Texturazition of multicrystalline silicon wafers solar cells by chemical treatment using metallic catalyst // Solar Energy Materials and Solar Cells. - 2006. - Vol. 90, - No.1. - P. $100-110$

17. P. Panek, M. Lipiski, J. Dutkiewicz. Texturization of multicrystalline silicon by wet chemical etching for silicon solar cells // Journal of Materials Science. - 2005. - Vol. 40, - No.6. - P. 1459-1463.

18. V.Y. Yerokhov, R. Hezel, M. Lipinski, R. Ciach, H. Nagel, A. Mylyanych, P. Panek, Cost-effective methods of texturing for silicon solar cells // Solar Energy Materials and Solar Cells. - 2012. - Vol. 72. - P. 291-298.

19. L.A. Dobrzaňski, A.Dragala. Surface texturing of multicrystalline silicon solar cells // Journal of Achievements in materials and manufacturing engineering. - 2008. - Vol. 31, No 1. - P. 77-82.

20. A. Gokce, A. Coskuner, G. Kosoglu, O. Altunay, M. Yumak, O. Ozatay, Y. Skarlato. A Porous Silicon Recipe for Si Solar Cell Applications // BAOJ Physics. - 2016. - Vol.1, No 1. - P. 1-7.

21. Kh.A. Salman, Z. Hassan, Kh. Omar. Effect of Silicon Porosity on Solar Cell Efficiency // International journal of electrochemical science. - 2012. - Vol. 7. - P. 376-386. 